\title{
Natural product C-glycosyltransferases - a scarcely characterised enzymatic activity with biotechnological potential
}

Putkaradze, Natalia; Tezé, David; Fredslund, Folmer; Welner, Ditte Hededam

Published in:

Natural Product Reports

Link to article, DOI:

10.1039/d0np00040j

Publication date:

2021

Document Version

Peer reviewed version

Link back to DTU Orbit

Citation (APA):

Putkaradze, N., Tezé, D., Fredslund, F., \& Welner, D. H. (2021). Natural product C-glycosyltransferases - a scarcely characterised enzymatic activity with biotechnological potential. Natural Product Reports, 38, 432-443. https://doi.org/10.1039/d0np00040

\section{General rights}

Copyright and moral rights for the publications made accessible in the public portal are retained by the authors and/or other copyright owners and it is a condition of accessing publications that users recognise and abide by the legal requirements associated with these rights.

- Users may download and print one copy of any publication from the public portal for the purpose of private study or research.

- You may not further distribute the material or use it for any profit-making activity or commercial gain

- You may freely distribute the URL identifying the publication in the public portal 


\section{Natural product $C$-glycosyltransferases - a scarcely characterised enzymatic activity with biotechnological potential}

Received 00th January 20xx, Accepted 00th January 20xx

DOI: $10.1039 / \times 0 \times x 00000 x$

\begin{abstract}
Natalia Putkaradze, ${ }^{a}$ David Teze, ${ }^{a *}$ Folmer Fredslund ${ }^{\mathrm{a}}$ and Ditte Hededam Welner ${ }^{\mathrm{a} *}$
$C$-glycosyltransferases are enzymes that catalyse the transfer of sugar molecules to carbon atoms in substituted aromatic rings of a variety of natural products. The resulting $\beta$ - $C$-glycosidic bond is more stable in vivo than most $O$-glycosidic bonds, hence offering an attractive modulation of a variety of compounds with multiple biological activities. While $C$-glycosylated natural products have been known for centuries, our knowledge of corresponding $C$-glycosyltransferases is scarce. Here, we discuss commonalities and differences in the known $C$-glycosyltransferases, review attempts to leverage them as synthetic biocatalysts, and discuss current challenges and limitations in their research and application.
\end{abstract}

\section{Introduction}

C-glycosylated natural products (C-GNPs) represent interesting compounds for drug discovery as well as in the chemical industries, including the food and cosmetic sectors. ${ }^{1,2}$ Indeed, several C-GNPs have been reported to display antimicrobial, antioxidant, antitumorigenic, hepatoprotective, antidiabetic, anti-nociceptive or anti-inflammatory activity. ${ }^{1,3}$ Some examples of C-GNPs are the flavone glucosides vitexin and isovitexin (antioxidant, antitumorigenic, anti-nociceptive and anti-inflammatory), 3,4 the dihydrochalcone glucoside nothofagin (antioxidant), ${ }^{5}$ the chromone glucoside aloesin (anti-inflammatory and anti-pigmentation) ${ }^{6,7}$ and the widely used natural food colorant anthraquinone glucoside carminic acid (natural red 4).8,9

Industrial C-GNPs are commonly extracted from natural sources, which strongly limits their availability and sustainability. As a result, chemists and biologists are encouraged to develop chemical and biocatalytic syntheses. ${ }^{10-12}$ Chemical $C$-glycosylation is challenging, wasteful as it requires several steps (protection, activation, deprotection), and is not always fully stereo- and regioselective on an aromatic ring..$^{10}$ Biocatalytic $C$-glycosylation is potentially a viable alternative to chemical synthesis, since it requires a single reaction step, can lead to high yields, and is an environmentally friendly process.

In Nature, $C$-glycosylation is catalysed by $C$-glycosyltransferases (C-GTs). These enzymes join an activated sugar molecule (for example a UDP-sugar) and an acceptor molecule (for example a flavonoid). The resulting $C$-glyosidic linkages are predominantly found in $C$-GNPs, with the notable exceptions of $C$-pentosides such as pseudouridine in $\mathrm{RNA}^{13}$ and post-translational

\footnotetext{
a. The Novo Nordisk Foundation Center for Biosustainability, Technical University of Denmark,DK-2800 Lyngby,Denmark.E-mail:datez@dtu.dk,diwel@biosustain.dk * Corresponding authors

+Electronic Supplementary Information (ESI) available: The enzymological data and sequences of reported C-glycosyltransferases. See DOI: 10.1039/x0xx00000x
}

tryptophan mannosylation in proteins. ${ }^{14}$ The topics on natural $C$-glycosylation and $C$-glycosyltransferases were previously reviewed. ${ }^{15-17}$ In this highlight, we focus exclusively on C-GTs that catalyse the formation of pyranoside $C$-GNPs. We review current knowledge of substrate scope, enzyme structure and mechanism, before taking a look at state-of-the-art in engineering and application.

\section{C-glycosidic linkages in natural products}

The majority of known $C$-GNPs are flavonoids, occurring as monoand di-C-glycosylflavonoids as well as $C$-glycosyl-O-glycosylflavonoids and acyl-C-glycosylflavonoids. ${ }^{18}$ Despite the fact that $C$-GNPs have been known and used for years, their biosynthetic routes and biological roles remain mostly unrevealed. They are hypothesized to function in defence processes in plants and animals ${ }^{19}$ and in defence and virulence in bacteria. ${ }^{20,21}$ It is assumed that in vivo, C-glycosylation modifies natural product transport, cellular compartmentalization, stability and autotoxicity. In contrast to $O$ - and $N$-glycosylated natural products, $C$-GNPs are rather scarce.

Aromatic $C$-glycosides such as $C$-GNPs present a few particularities among $C$-glycosides in general. $C$-glycoside also refers to artificial mimics of $\mathrm{O}$-glycosides in which the glycosidic oxygen has been replaced by a $\mathrm{CH}_{2}$ group. Owing to their improved stability towards enzymatic and acidic deglycosylation, as well as their close conformational resemblance with the original $\mathrm{O}$-glycosides, the synthesis and application of such methylene $C$-glycosides are active fields of research. ${ }^{10}$ However, all reported naturally occurring $C$-glycosidic bonds in C-GNPs link a sugar to a carbon within an aromatic ring (Figs. 1 and 2). Thus, they cannot lead to geometries comparable to $O$ - and $S$-glycosylation but are more akin to the well-known $\mathrm{N}$-glycosylation observed in nucleosides, with few degrees of conformational freedom. While $O$-glycosylation can stabilize natural products by protecting a reactive hydroxyl group, such as in dhurrin ${ }^{22}$ or 


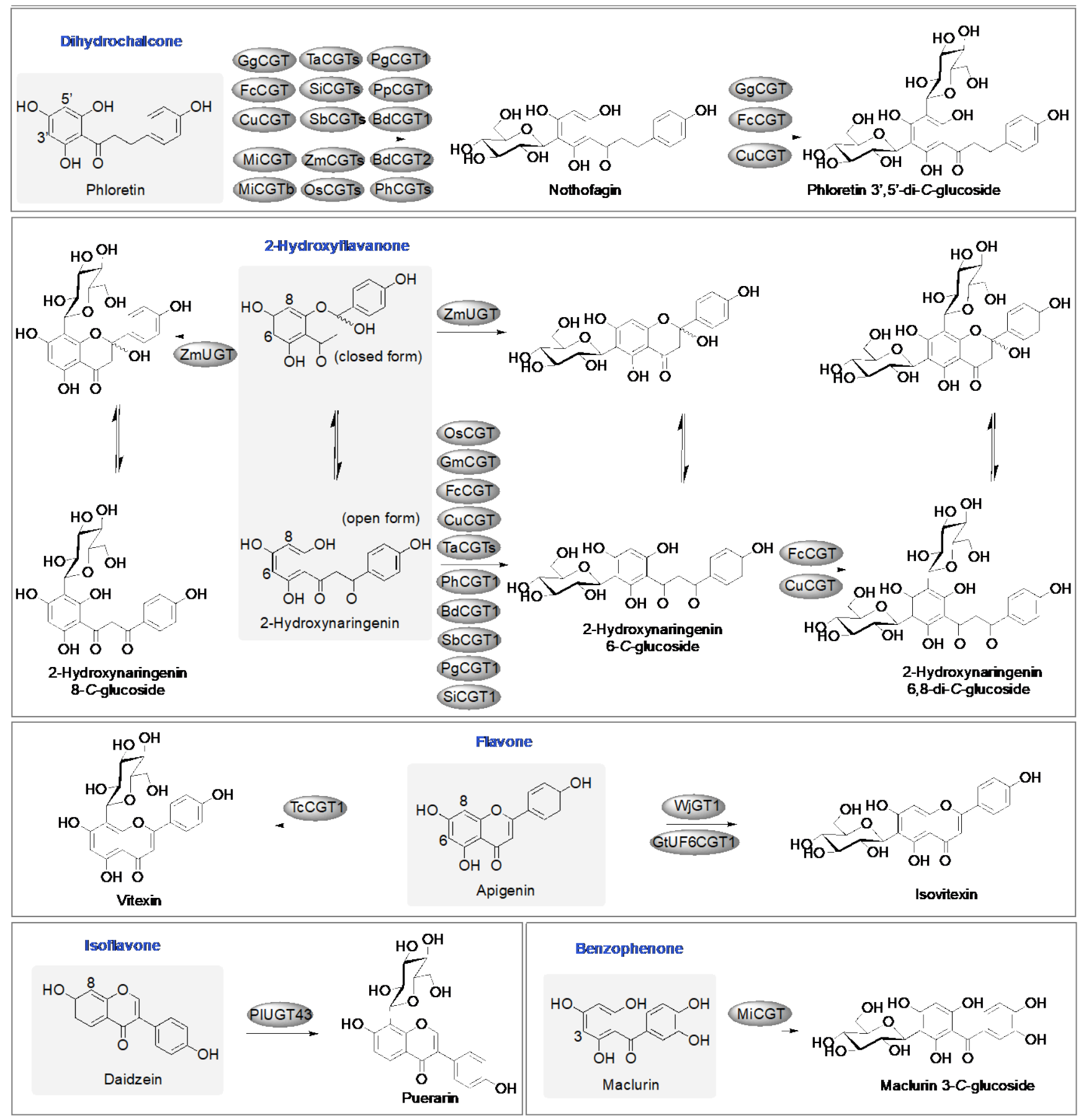

Fig. 1 Common aglycons and reactions of plant C-GTs. TaCGTs, OsCGTs, ZmCGTs, SbCGTs, SiCGTs and PhCGTs represent several $C$-GTs from $T$. aestivum, $O$. sativa, Z. mays, S. bicolor, S. italica and P. heterocycla, respectively. ${ }^{28,30}$ Note that the $3^{\prime}$ and $5^{\prime}$ positions of phloretin, as well as the 6 and 8 positions of the open form of 2-hydroxynaringenin are chemically equivalent.

indican, ${ }^{23} \mathrm{C}$-glycosylation cannot have this effect. Hence, $C$ - and $O$-glycosylation are not analogous: they occur at different positions, lead to different geometries ( $\mathrm{sp}^{2} \mathrm{vs} \mathrm{sp}^{3}$ hybridization), and have different functions. Moreover, if aryl $C$-glycopyranosidic bonds are almost exclusively $\beta$-, even $\alpha$-ones are predominantly equatorial. Indeed, it has been shown that aryl $\alpha$ - $C$-D-olivosides are found in a ${ }^{1} C_{4}$ conformation, pushing three substituent in axial, to preserve the anomeric aryl as the only equatorial substituent. ${ }^{12,24}$ This pseudo-requirement for an equatorial glycosidic bond is likely accounts for the scarcity of
$\alpha$-C-D-glycopyranosides. However, glycosylation at any position will change the physicochemical properties of the compound, such as decreasing volatility or increasing water solubility, and thereby modify compartmentalization. Moreover, C-glycosidic bonds in natural products appear to be resistant to most enzymatic cleavage, with only a few reports about the cleavage of $C$-glycosidic bonds of puerarin (a $C$-glucosylisoflavone with potential medical applications) by human gut bacteria. Particularly, a three-protein complex capable of catalysing the $C$-glucosidic bond cleavage in puerarin has been partially 
purified. ${ }^{25}$ However, the deglycosylation mechanism(s) of C-GNPs is largely unknown. ${ }^{26}$ This biological stability of the glycosylation in C-GNPs render them attractive synthetic targets.

\section{C-glycosyltransferases}

While C-GNPs have been known for centuries, ${ }^{27}$ C-GTs have only recently been identified, predominantly during the last few years. Notably, there is now 54 known C-GTs, 30 of which were identified this year. ${ }^{28}$ These $C$-GTs are inverting glycosyltransferases belonging to the GT1 family in the CAZy classification (www.cazy.org). ${ }^{29}$ Hence, they are phylogenetically related and catalyse the formation of a $\beta$-glycosidic bond between a carbon in an aromatic ring and the anomeric centre of a monosaccharide, provided by an electrophilic and activated $\alpha$-glycoside. The few kinetic studies available indicate $K_{\mathrm{m}}$ values in the micromolar range and $k_{\text {cat }}$ values in the $0.1-10 \mathrm{~s}^{-1}$ range (Supplementary Table 1).

\subsection{Plant $C$-glycosyltransferases}

The majority of characterised C-GTs (Table 1 ) originate from plants, specifically cereals and legumes (rice, ${ }^{30}$ maize, ${ }^{31}$ soybean, ${ }^{32}$

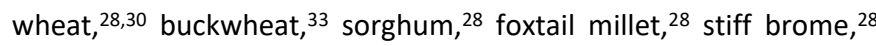
bamboo, 28 kudzu, ${ }^{34}$ liquorice ${ }^{35}$ ), citrus (mandarin, kumquat, hanaju), ${ }^{36}$ medicinal plants (gentian, ${ }^{37}$ trollius ${ }^{38}$ ), and other plant species (mango, ${ }^{39}$ wasabi, $^{40}$ arabidopsis ${ }^{41}$ ). A few $C$-GT genes or gene fragments are also reported in date palm, yam and orchid. ${ }^{28}$ These plant C-GTs share $22-99 \%$ sequence identity with each other, with intraspecies identity varying from $94-99 \%$ (citrus, $^{36}$ rice, ${ }^{28,30}$ maize, ${ }^{28,31}$ buckwheat ${ }^{33}$ ) to $48-54 \%$ (rice, ${ }^{28,30}$ maize ${ }^{28,31}$ ).

All known plant C-GTs are UDP-dependent glycosyltransferases (UGTs), meaning they use UDP-activated sugars as donor substrates. UDP-glucose is the most common sugar donor, but UDP-arabinose, -galactose, -xylose, -glucuronate, and $-N$-acetylglucosamine have also been reported as substrates for individual plant $C$-GTs (Table 1 ). Various compound classes have been found as C-GNPs in Nature, including flavonoids, xanthones, chromones, anthrones and anthraquinones. ${ }^{19,42}$ Although all these classes are probably glycosylated by C-GTs in Nature, characterised enzymes so far present acceptor specificities restricted to flavonoids (most using 2', $4^{\prime}, 6^{\prime}$-trihydroxyacetophenone-like structures), $30,33,35,36,40$ with the notable exceptions of MiCGT and UGT73s/UGT74E2 which are able to $C$-glycosylate xanthones ${ }^{43}$ and nitrobenzene derivatives ${ }^{41}$, respectively. Substrates of reported C-GTs are summarized in Table 1 and archetypical reactions catalysed by plant $C$-GTs are shown in Fig. 1.

The first plant C-GTs were reported in 2008 while $C$-glycosylation activity of enzyme preparation from buckwheat cotyledons was observed in 1987.44,45 These were bifunctional $O$ - and C-GTs (5 UGT73s and UGT74E2 from $A$. thaliana) ${ }^{41}$ involved in detoxification of the explosive pollutant 2,4,6-trinitrotoluene (TNT) via $O$ - and $C$-glycosylation of its metabolites 2-hydroxylamino-4,6-dinitrotoluene (2-HADNT) and/or 4-hydroxylamino-2,6-dinitrotoluene (4-HADNT), suggesting a function in xenobiotic metabolism. ${ }^{41}$ This discovery was followed by the identification of an enzyme from Zea mays (UGT708A6, 2013) 31 exhibiting $\mathrm{O}$-glycosylation activity towards the flavanones naringenin and eriodictyol, and C-glycosylation activity towards 2-hydroxyflavanones. Since then, several C-GTs from other plants have been characterised without concomitant demonstration of $O$-glycosylation activity (OsCGT from Oryza sativa, ${ }^{30} \mathrm{FeCGTa}$ and FeCGTb from Fagopyrum esculentum M,33 UGT708D1 from Glycine max, ${ }^{32}$ FcCGT from Fortunella crassifolia and CUCGT from Citrus unshiu $\left.{ }^{36}\right)$. Most of these enzymes have activity on 2-hydroxynaringenin. Closed and open forms of 2-hydroxynaringenin are in equilibrium, and all 2-hydroxyflavanone $C$-GTs except for the aforementioned UGT708A6 are acting on the open form (Fig. 1). The number of known 2-hydroxyflavanone $C$-GTs drastically increased with a recent study (2020) in which 26 new plant enzymes from Oryza sativa, Triticum aestivum, Zea mays, Sorghum bicolor, Setaria italica, Brachypodium distachyon and Phyllostachys sp. were reported to have $C$-glycosylation activity towards 2-hydroxynaringenin. ${ }^{28}$ Most of these enzymes as well as four other C-GTs (PpCGT1, OsCGT4, PhCGT4 and ZmCGT2) were found to also act on the dihydrochalcone phloretin. ${ }^{28}$ Phylogenetically, they are separated into two clades, with members of the first clade strongly preferring UDP-glucose and members of the second clade utilizing both UDP-glucose and UDP-arabinose as donors and favouring phloretin as acceptor substrate (Table 1). ${ }^{28}$ A DPFXL/V motif was proposed to be predictive for 2-hydroxyflavanone C-GT activity, ${ }^{38}$ yet a few DPFXL/V-containing C-GTs (ZmCGT2, PpCGT1, PhCGT4) are reported to be accepting phloretin instead. ${ }^{28}$

In addition to the relatively large number of 2-hydroxyflavanone C-GTs, three flavone C-GTs are characterised: GtUF6CGT1 from Gentiana triflora ${ }^{37}$ and WjGT1 from Eutrema japonicum ${ }^{40}$ with activity towards apigenin and luteolin and TcCGT1 from Trollius chinensis ${ }^{38}$ with activity towards various flavones. Furthermore, a C-GT from Pueraria lobata (PIUGT43), is acting on the isoflavones daidzein and genistein. ${ }^{34}$

Interestingly, PIUGT43 and GtUF6CGT1 demonstrate strict acceptor specificity; they act on isoflavones and flavones, respectively, but show no activity towards flavanones, 2-hydroxyflavanones or flavonols. ${ }^{34,37}$ Conversely, WjGT1 and TcCGT1 both accept flavanone and flavonol aglycons, and TcCGT1 is additionally active on the 2-hydroxyflavanone 2-hydroxypinocembrin. MiCGT ${ }^{43}$ and MiCGTb ${ }^{46}$ (Mangifera indica), and GgCGT 35 (Glycyrrhiza glabra), also display remarkable acceptor promiscuity; MiCGT glycosylates many natural and unnatural drug-like molecules, predominantly with 2,4,6-trihydroxybenzophenone-like core structures, ${ }^{43}$ TcCGT1 is capable of 8-C-glycosylation of 36 flavones and related compounds, ${ }^{38}$ and GgCGT can act on 33 phenolic aglycons, 6 of which are di-C-glycosylated. ${ }^{35}$ Moreover, the number and the position of hydroxyl groups in the aglycon structure governs the balance between $C$ - and $O$-activities of bifunctional plant $C$-GTs. ${ }^{31,43}$

Finally, besides the several bifunctional $O$-/C-GTs (UGT73B4/C1, ${ }^{41}$ UGT708A6, ${ }^{31}$ OsCGT, ${ }^{30}$ MiCGTb $^{46}$ and UrdGT2 ${ }^{47}$ ), MiCGT ${ }^{43}$ exhibits additional $\mathrm{N}$-glycosylation activity, and TCCGT1 ${ }^{38}$ and GgCGT ${ }^{35}$ are able to catalyse the formation of all four types $\left(\mathrm{C}_{-}, \mathrm{O}_{-}, \mathrm{N}-, \mathrm{S}_{-}\right)$of glycosidic linkages. It is likely that more enzymes are multifunctional but have yet to be tested against relevant acceptors. 


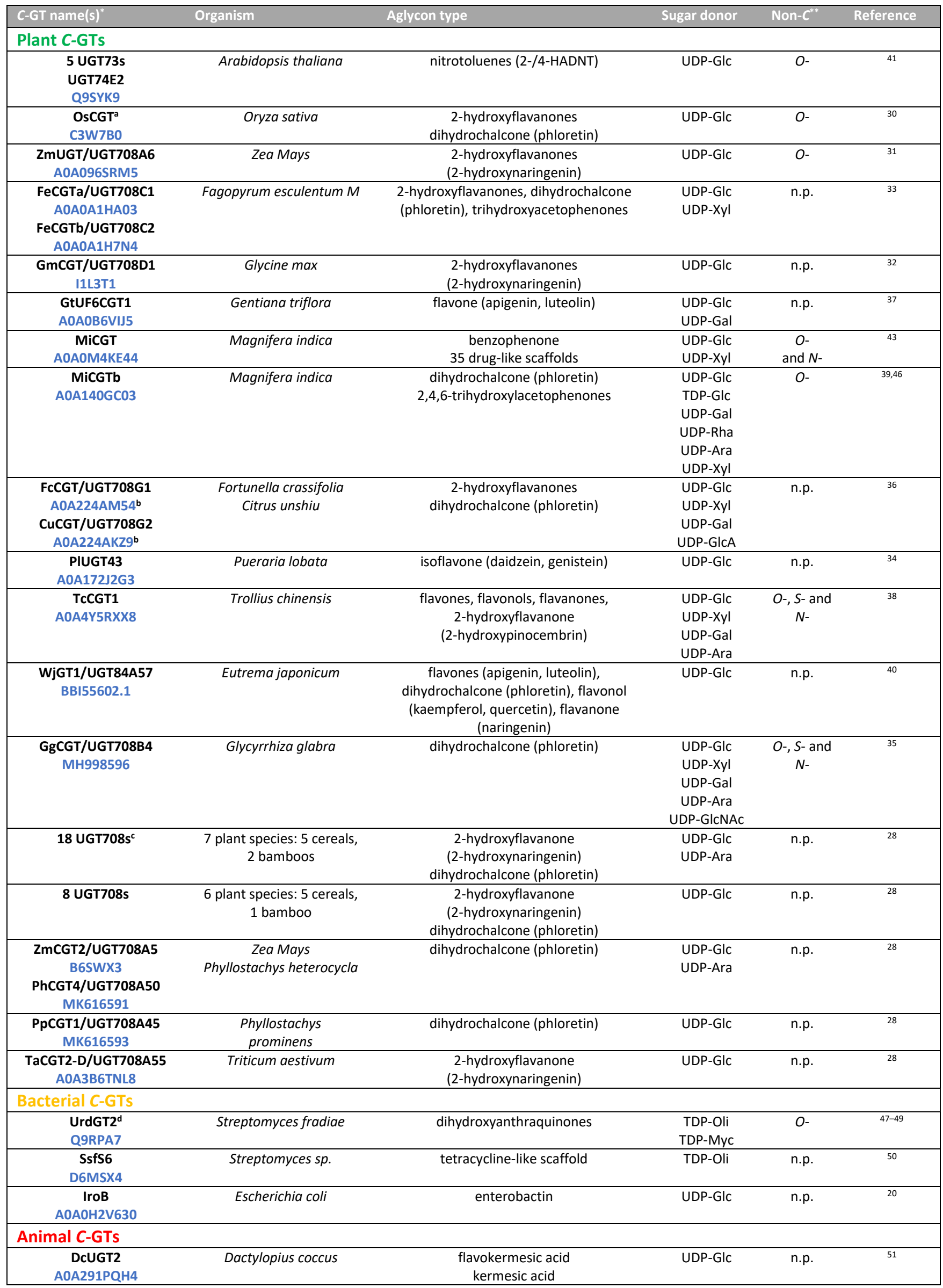

Table 1 Substrates of characterized C-GTs. n.p. - not provided. " name of $C$-GTs according to the references (black) and their Uniprot/Genbank IDs (blue).

** other glycosylation activities $\left(\mathrm{O}-, \mathrm{N}-\mathrm{S} \mathrm{S}\right.$ ) reported. Rha - rhamnose, GlcA - glucuronate, Oli - olivose, Myc - mycarose. ${ }^{\mathrm{a}} \mathrm{crude}$ activity of a similar protein in Triticum aestivum reported. ${ }^{30}$ bimilar protein (ChCGT/UGT708G3, Uniprot: A0A224AMA5) reported from Citrus hanaju but not characterized. ${ }^{36}$

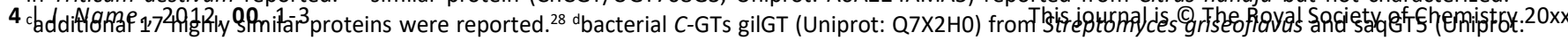
C4NYL6) from Micromonospora sp. Tü6368 reported to be involved in the biosynthesis of gilvocarcin $\mathrm{V}^{52}$ and saquayamycin $\mathrm{Z}^{53}$, respectively. 

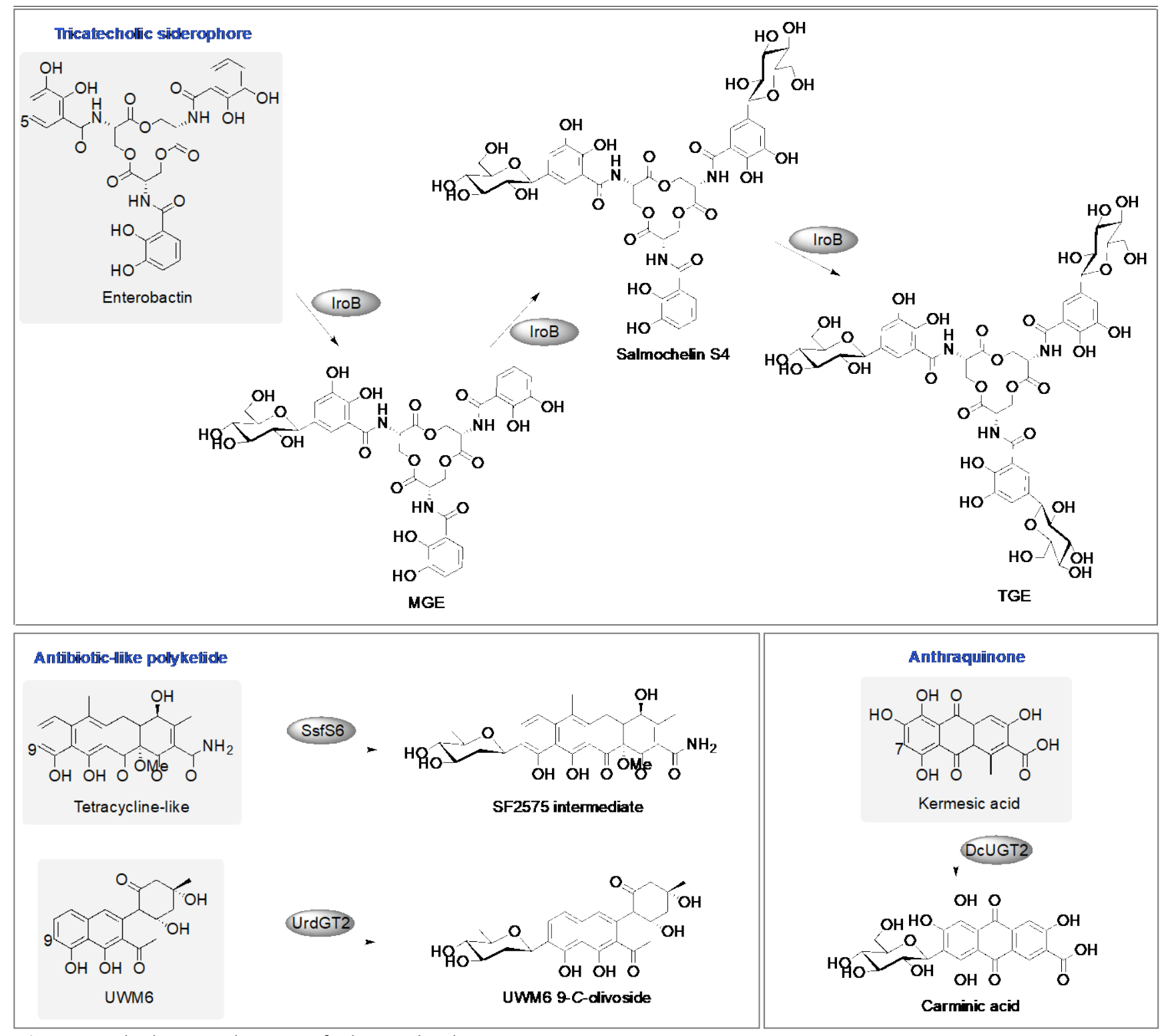

Fig. 2 Natural aglycons and reactions for bacterial and insect $C$-GTs.

\subsection{C-glycosyltransferases from other organisms}

Four C-GTs from organisms outside the plant kingdom have been characterised: three enzymes from bacteria (UrdGT2 from Streptomyces fradiae, ${ }^{49}$ IroB from Escherichia coli ${ }^{20}$ and SsfS6 from Streptomyces $s p{ }^{54}$ ) and one from a scale insect (DcUGT2 from Dactylopius coccus ${ }^{51}$ ). They share less than $32 \%$ sequence identity with each other and less than $20 \%$ with plant C-GTs. They use diverse nucleotide glycoside donors (UDP-glucose, TDP-olivose, TDP-mycarose, NDP-rhodinose ${ }^{55}$ ), and catalyse sugar transfers to structurally different, generally bulkier and more complex aglycons than their plant counterparts. In addition to these characterised enzymes, putative bacterial $C$-GTs gilGT and saqGT5 have been proposed to be involved in the synthesis of gilvocarin ${ }^{52}$ and saquayamycin $Z,{ }^{53}$ respectively. Their C-GT activity was confirmed through gene inactivation in vivo, but not in vitro so far. Furthermore, Streptomyces sp. genes gra-ORF $14^{56}$ and med-ORF $8^{57}$ were proposed to encode $C$-GTs involved in the biosynthesis of benzoisochromanequinone antibiotics.
UrdGT2 from Streptomyces fradiae is the most investigated C-GT, 48,49,58 and is involved in the biosynthesis of the antibiotic urdamycin. ${ }^{58}$ UrdGT2 is not a UGT, but utilises TDP-olivose and TDP-mycarose. In $S$. fradiae, it transfers D-olivose to 2-hydro-3-hydroxy-prejadomycin (UWM6) to form UWM6 9-C-olivoside (Fig. 2). ${ }^{59}$ UrdGT2 has shown high tolerance not only for accepting natural and synthetic aglycons in vivo (premithramycinone, 4-O-demethyl premithramycinone, tetrangulol) ${ }^{60,61}$ but also for utilisation of stereochemical variations of different glycoside donors (NDP-D-rhodinose, NDP-L-rhodinose). ${ }^{55,62}$ Furthermore, UrdGT2 is capable of generating both $C$ - and $O$-glycosidic linkages. ${ }^{47}$ Another bacterial $C-\mathrm{GT}$, IroB from pathogenic $E$. coli acts on the tricatecholic iron-sequestering compound (siderophore) enterobactin. ${ }^{20} \mathrm{~A}$ similar protein is assumed to be expressed in Salmonella enterica since glycosylated enterobactins have been previously isolated from this microorganism. ${ }^{63}$ Enterobactins are used by bacteria to survive under low-iron stress and $C$-glucosylation hinders the sequestration of this siderophore by 
mammalian proteins, increasing bacterial virulence. ${ }^{21}$ IroB was characterised in vitro and found to catalyse three sequential glycosylations of enterobactin at position $C-5$ of the 2,3-dihydroxybenzoyl ring, using UDP-glucose as glycosyl donor to form monoglucosyl-C- (MGE), diglucosyl-C- (DGE, salmochelin S4) and triglucosyl-C-enterobactin (TGE). ${ }^{20,64}$ SsfS6 from Streptomyces $s p$. uses a tetracycline-like compound (Fig. 2) as acceptor in the biosynthesis of the tetracycline compound SF2575..$^{50,54}$

DcUGT2 is the only animal C-GT identified so far. ${ }^{51}$ Its closest homolog (46\% sequence identity) is the putative glucuronosyltransferase 2B10 from the insect Acyrthosiphon pisum. It is the only known membrane-bound $C$-GT (endoplasmic reticulum) and has been functionally characterised using yeast microsomal fraction in vitro. DcUGT2 is involved in the biosynthesis of the red pigment carminic acid, transferring glucose from UDP-glucose to flavokermesic and kermesic acids. 51

\subsection{Structural characterisation of $C$-glycosyltransferases}

There are currently four structurally characterised natural C-GTs (Fig. 3); two plant (TcCGT1 ${ }^{38}$ and $\mathrm{GgCGT}^{35}$ ) and two bacterial enzymes (UrdGT2 ${ }^{59}$ and $\mathrm{SsfS}^{54}$ ). The overall structural organisation of all four enzymes is very similar to relatives from the GT1 family able to catalyse the formation of $\mathrm{O}-, \mathrm{N}_{-}$, or $S$-glycosidic bonds. ${ }^{35,38,54,59}$ They display the GT-B type fold, 65,66 with an active site cleft formed between two $\beta / \alpha / \beta$ Rossmannlike domains. The two bacterial enzymes present themselves as homodimers, whereas the two plant enzymes are monomeric, and roughly 100 amino acids longer in sequence than their bacterial counterparts.

The N-terminal Rossmann domain, which contains both the catalytic machinery and the aglycon binding pocket differ between plant and bacterial C-GTs in two major ways. First, the active site of both plant enzymes (TcCGT and GgCGT) contains a His-Asp dyad in the vicinity of the reaction centre, a motif referred to as catalytic in many GT1 enzymes. ${ }^{67}$ The function of these residues has not been experimentally verified for $C$-glycosylation. Strikingly, this dyad is not found in the bacterial C-GT structures, and no other potential catalytic base has been identified. It should be noted, that closely related bacterial GT1 enzymes do present this dyad (Supplementary Fig. 1). Second, both bacterial and plant enzymes have a helix between $\beta$-sheets 3 to 4 (purple), but the bacterial helices are longer and spanning the entire width of the aglycon binding site, whereas this space is covered by two regions between $\beta$-sheet $3 / 4$ and $5 / 6$ (green) in the plant enzymes (Fig. 3).

\subsection{Engineering of $C$-glycosyltransferases}

Interest in C-GT mediated catalysis as well as in structura determinants that control substrate recognition and reaction specificity (particularly $C$ - vs $O$ - activities) initiated a handful of mutational analysis and engineering studies. These aimed to redesign known $O$-GTs into $C$-GTs, 68,69 or to identify important catalytic residues of $C$-GTs based on their structures - being experimentally determined 35,38 or obtained via homology modelling. ${ }^{39,64}$
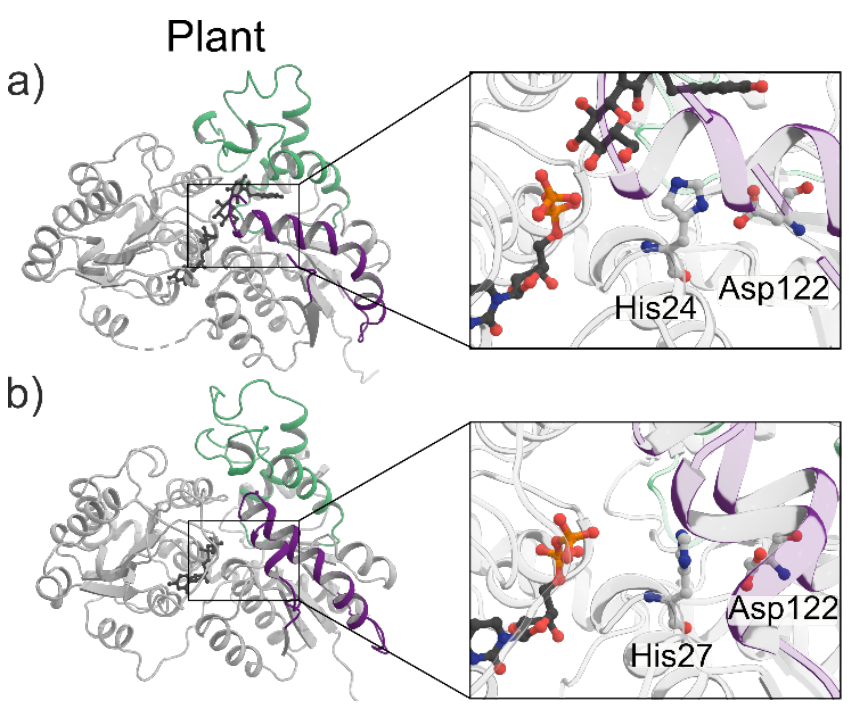

\section{Bacterial}

c)

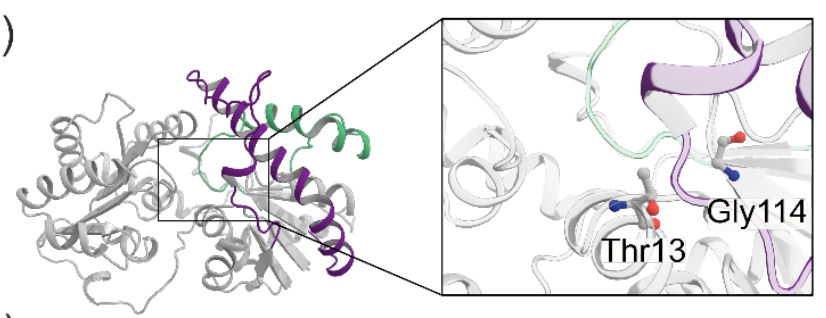

d)

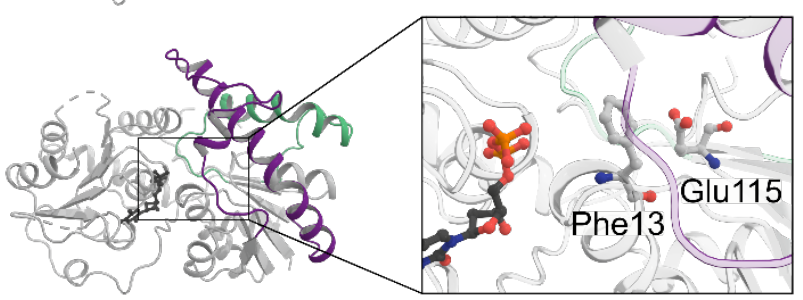

Fig. 3 Structures of $C$-GTs. Two regions between $\beta$-sheets within the $\mathrm{N}$-terminal Rossmann domain are highlighted: purple, $\beta$-sheet $3 \rightarrow 4$; green, $\beta$ sheet $5 \rightarrow 6$. A close-up on the active site is provided, where the residues at the positions corresponding to the His-Asp catalytic dyad are shown as sticks. a) GgCGT (PDB ID:6L7H) with UDP and nothofagin, b) TCCGT (PDB ID:6JTD) with UDP, c) UrdGT2 (PDB ID:2P6P), d) SsfS6 (PDB ID:4G2T) is shown with TDP.

An O-GT from Streptomyces cyanogenus S136, LanGT2, was converted into a $C$-GT based on primary sequence comparison with the closely related (53\% identity) C-GT UrdGT2 by applying computational modelling and structure-based mutagenesis. ${ }^{68} \mathrm{~A}$ loop region ${ }^{51}$ VATTDLPIRHFI ${ }^{62}$ in UrdGT2 and LanGT2S8Ac (the C-GT variant of LanGT2 ), ${ }^{51}$ LSIAPSSIRRYA ${ }^{62}$ in the wild type of LanGT2) was found to be crucial for the $\mathrm{O}$ - or $\mathrm{C}$-glycosylation specificity, and a follow-up structural and computational study proposed an inducedfit conformational transition as the determining factor between these two activities. ${ }^{70}$ Particularly, the acceptor binding pocket of the LanGT2S8Ac was found to be more compact than that of LanGT2-wt and the orientation of the residue 158 crucial in positioning the substrate for $C$-glycosylation (Supplementary Fig. 2). The importance of the acceptor binding mode for $C$-versus $O$-glycosylation selectivity was also observed in another engineering study on TcCGT in which a shrinkage of the spacious binding pocket (via a salt bridge introduction with the $194 \mathrm{E}$ and G284K substitutions) completely 
abolished $C$-glycosylation activity, converting the enzyme to an O-GT. ${ }^{38}$

An active site motif ${ }^{120} \mathrm{DI}^{121}$ containing the Asp of the proposed catalytic dyad in OsCGT corresponding to ${ }^{117} \mathrm{ID}^{118}$ in an $O$-GT from Pyrus communis, PCOGT, was identified as reversible switch between $C$ - and $O$-glycosylation activities towards phloretin. ${ }^{69}$ However, the obtained OsCGT and PCOGT variants with changed glycosylation specificities had dramatically decreased catalytic activities $\left(10^{3}-\right.$ $10^{4}$-fold) compared to the native enzymes. By applying homology modelling to IroB based on UrdGT2 and SsfS6 structures, E67, W264 and D304 were suggested as important for efficient IroB catalysis. ${ }^{64}$ Determinants between mono- and bis-C-GT activities have also been probed. By investigating structural differences MiCGT (mono-) and MiCGTb (bis-C-GT, 91\% identity to MiCGT) via structure-based sequence alignment and applying site-directed mutagenesis, key residues have been predicted and probed. ${ }^{39}$ S60, V100 and T104 were determined important and 1152 essential for bis-C-GT activity. Eight quadruple mutants with improved bis-C-GT were generated based on saturation mutagenesis at positions 60, 100, 104 and 152 and combining the optimal residues. The two best variants (MiCGTb-GAGM and MiCGTb-KAGM) showed 4.2-fold increased activity. ${ }^{39}$ Moreover, a few of the quadruple mutants showed broader donor promiscuity by using different $\alpha$-D- and $\beta$-L-glycosyl donors such as UDP- $\beta$-L-fucose, UDP- $\alpha$-D-N-acetyl-glucosamine and GDP- $\alpha$-D-mannose. Besides that, a mutant MiCGT-E152L with high acceptor tolerance were reported in the same study. ${ }^{39}$ In another study, G389 was found to be critical for di-C-glycosylation activity in GgCGT and a single mutation G389K almost completely shifted di-C to mono-C-glycosylation. ${ }^{35}$

\subsection{Mechanistic insights into enzymatic $C$-glycosylation}

In organic chemistry, the formation of $C$-glycosidic bonds can occur through many different mechanisms; radical-mediated, metalcatalysed reactions, with nucleophilic or electrophilic glycosidic precursors, etc. ${ }^{10,12}$ Although the fine mechanism of $C$-GTs has not been firmly established, we know that it leads to the formation of a $\beta$-glycosidic bond from an $\alpha$-glycoside donor, and unto a carbon atom within an aromatic ring, usually at an ortho position relative to a heteroatom-bearing carbon. Hence, the anomeric carbon of the donor acts as an electrophilic centre, and a carbon on the aromatic ring as a nucleophilic centre. Since quite a few $C$-GTs are able to also catalyse the formation of $\mathrm{O}$-glycosidic bonds, it has been proposed that the catalytic His-Asp dyad mentioned above and known from the related $O$-glycosylating UGTs (Scheme 1 a) also plays a catalytic role in $C$-glycosylation. ${ }^{17}$ Specifically, it would deprotonate the heteroatom ortho to the $C$-glycosylation site on the aromatic ring. This would lead to a transient non-aromatic glycosylated compound, before restauration of aromaticity through tautomerisation (Scheme 1b). The strong decrease in $\mathrm{C}$-glycosylation activity of the OsCGT ${ }^{71}$ and UGT708C172 enzymes when their likely catalytic bases (respectively His24 and His32) are mutated into alanine, are supportive of such a mechanism, currently the most accepted one. ${ }^{16}$ However, there is no ortho-hydroxyl group of the glucoside moieties in enterobactins (Fig. 2). ${ }^{20}$ It can be argued that this mechanism can still apply, except deprotonation would happen at the para-hydroxyl group and electrons would subsequently delocalize through the aromatic ring (Scheme 1c), 64 a mechanism consistent with the observation that heteroatoms containing functional groups have been observed as being either ortho- or para-director, but not meta. It should be noted here that for some C-GTs, no enzymatic base candidate has been identified. It may be that an enzymatic base is yet to be discovered, that these enzymes use water-mediated base catalysis such as proposed for LanGT2,70 or that some of the polyphenolic acceptors are acidic enough to be deprotonated at neutral $\mathrm{pH}$, e.g. phloretin with a $\mathrm{p} K_{\mathrm{a}}$ of $7.4,{ }^{73}$ negating the need for an enzymatic base (Scheme $1 \mathrm{~d}$ ). An aromatic electrophilic

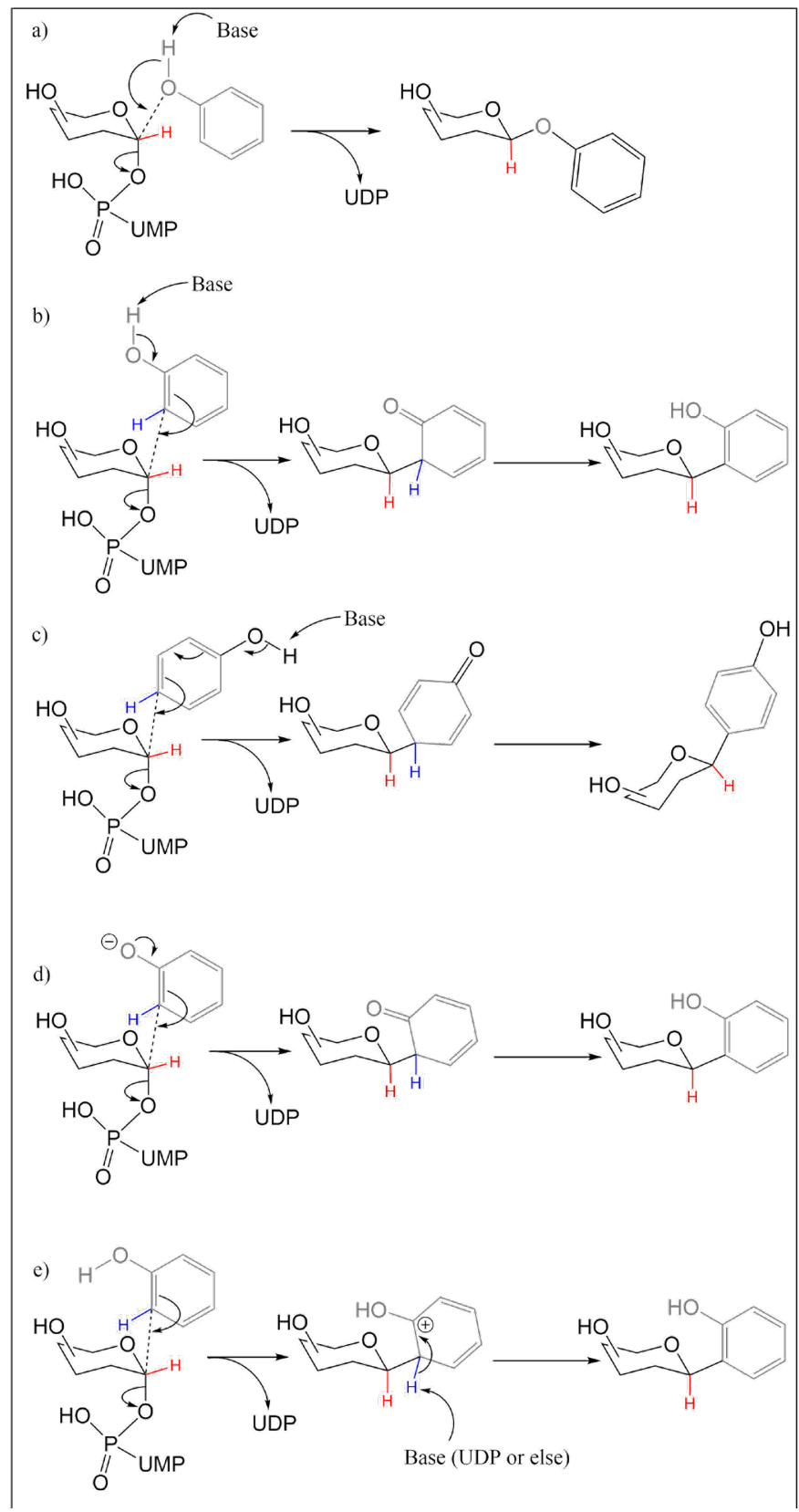

Scheme 1 Possible C-GT mechanisms: a) O-glycosylation mechanism. b) $\mathrm{O}$-glycosylation inspired mechanism, followed by tautomerisation. c) with a para-hydroxyl group. d) with a deprotonated acceptor. e) $\mathrm{S}_{\mathrm{E}} \mathrm{Ar}$ preceding deprotonation. ${ }^{41}$ 
substitution $\left(S_{E} A r\right)$ occurring before deprotonation cannot be ruled out, leading to a positively charged intermediate (Scheme 1e). Such a mechanism would not necessarily require an enzymatic base, as the departing group from the donor substrate could act as a base. However, it would require the development of a positive charge in the vicinity of and above the anomeric carbon, itself bearing a large partial positive charge during catalysis, rendering such a mechanism unlikely. Moreover, $\mathrm{C}$-glycosylation activities against dinitrotoluene derivatives have been reported, ${ }^{41}$ and nitro groups would strongly reduce the ring reactivity. Another alternative theory, likewise relying on the observation that $O$ - and $C$-glycosylation tend to go hand-in-hand, would be that catalysis proceeds through $O$ glycosylation followed by an $O$ - to $C$ - rearrangement. However, such a mechanism has been deemed highly unlikely as the enzyme would need to be able to stabilize multiple transition states along this multistep reaction. ${ }^{17}$ It is further discredited by $C$-glycosylation events without ortho-hydroxyl group to the glycosylation site, and by the experimental study of OsCGT and its I121D mutant. ${ }^{69}$
Overall, the C-GT mechanism likely involves deprotonation (by an enzymatic base or not), a nucleophilic attack on the anomeric carbon, and a subsequent tautomerisation restoring aromaticity (Scheme $1 b-d$ ). It would thus require the presence of a heteroatom as a substituent on the aromatic ring in an ortho- or para-position relative to the $C$-glycosylation site.

\section{Application of $C$-glycosyltransferases in biotechnology}

As for other glycosyltransferase-catalysed synthesis, application of C-GTs for the industrial production of C-GNPs is currently limited. ${ }^{85}$ Several groups have already been inspired to develop methods for the catalytic production of beneficial C-GNPs by applying C-GTs in vitro as well as in whole-cell approaches on lab scale (Table 2). Based on the catalytic performance of reported C-GT-based biocatalysts it can be generally concluded that extensive optimisations are required to reach industrial scale. Previous studies clearly demonstrate the

\begin{tabular}{|c|c|c|c|c|}
\hline $\begin{array}{l}\text { Reaction type } \\
\text { /Host }\end{array}$ & C-GT* & $\begin{array}{l}\text { Aglycon }{ }^{* *} \rightarrow C-G N P \\
\text { /C-GNP }\end{array}$ & $\begin{array}{l}\text { Product concentration } \\
\text { /Conversion }\end{array}$ & Reference \\
\hline \multicolumn{5}{|l|}{ In vitro } \\
\hline & MiCGTb & $\begin{array}{l}\text { acylphloroglucinol } \\
\text { 2-O-glucosides } \rightarrow \\
\text { acylphloroglucinol } \\
\text { 3-C-glucosides }\end{array}$ & $\begin{array}{c}>80 \% \text { conversion of } 0.2 \\
\mathrm{mM}\end{array}$ & 46 \\
\hline & $\begin{array}{l}\text { OsCGT (PcOGT) } \\
\text { OsCGT-I121D }\end{array}$ & phlorizin $\rightarrow$ nothofagin & $\begin{array}{l}50 \% \text { conversion of } 5 \mathrm{mM} \\
70 \% \text { conversion of } 0.5 \mathrm{mM}\end{array}$ & 74 \\
\hline & OsCGT (GmSuSy) & phloretin $\rightarrow$ nothofagin & $20-50 \mathrm{~g} \cdot \mathrm{L}^{-1}$ & 75,76 \\
\hline & GtUF6CGT1 & apigenin $\rightarrow$ isovitexin & $3.8 \mathrm{~g} \cdot \mathrm{L}^{-1}$ & 77 \\
\hline & GtUF6CGT1 & luteolin $\rightarrow$ isoorientin & $3.8 \mathrm{~g} \cdot \mathrm{L}^{-1}$ & 77 \\
\hline \multicolumn{5}{|l|}{ In vivo } \\
\hline S. cerevisiae & OsCGT (several enzymes) & nothofagin & $59 \pm 6 \mathrm{mg} \cdot \mathrm{L}^{-1}$ & 5 \\
\hline $\begin{array}{c}\text { E. coli } \\
\text { S. cerevisiae }\end{array}$ & $\begin{array}{c}\text { GtUF6CGT1 (several } \\
\text { enzymes) } \\
\text { PhCGT1 (several enzymes) } \\
\text { FeCGTb (OsF2H/SbF2H) }\end{array}$ & $\begin{array}{l}\text { various flavone } \\
\text { C-glucosides }\end{array}$ & $\begin{array}{c}42 \mathrm{mg} \cdot \mathrm{L}^{-1} \\
45.8 \pm 14.9 \mathrm{mg} \cdot \mathrm{L}^{-1} \\
140 \mathrm{mg} \cdot \mathrm{L}^{-1}\end{array}$ & $\begin{array}{l}79 \\
28\end{array}$ \\
\hline E. coli & FeCGTa & $\begin{array}{l}\text { 2-hydroxyflavanone } \rightarrow \\
\text { 2-hydroxyflavanone } C \text { - } \\
\text { glucosides }\end{array}$ & n.p. & 78 \\
\hline S. cerevisiae & OsCGT (OsF2H) & $\begin{array}{l}\text { 2-hydroxynaringenin } C \text { - } \\
\text { glucoside }\end{array}$ & $8.2 \mathrm{mg} \cdot \mathrm{L}^{-1}$ & 81 \\
\hline E. coli & $\begin{array}{c}\text { FeCGTa } \\
\text { MiCGTb_GAGM }\end{array}$ & $\begin{array}{c}\text { acetophenone } \rightarrow \\
\text { acetophenone } \\
C \text {-glucosides } \\
\end{array}$ & $\begin{array}{c}\text { n.p. } \\
970 \mathrm{mg} \cdot \mathrm{L}^{-1}\end{array}$ & $\begin{array}{l}78 \\
82\end{array}$ \\
\hline E. coli & SsfS6 (several enzymes) & $\begin{array}{c}\text { anhydrotetracycline } \\
\text { 9-C-olivoside }{ }^{a}\end{array}$ & n.p. & 50 \\
\hline A. nidulans & DcUGT2 (several enzymes) & carminic acid & n.p. & 8 \\
\hline $\begin{array}{c}\text { A. nidulans } \\
\text { N. benthamiana }\end{array}$ & DcUGT2 (several enzymes) & $\begin{array}{l}\text { flavokermesic acid 7-C- } \\
\text { glucoside (dcll) }\end{array}$ & $\begin{array}{l}\text { n.p. } \\
\text { n.p. }\end{array}$ & $\begin{array}{c}8 \\
84 \\
\end{array}$ \\
\hline
\end{tabular}

Table 2 C-GT-catalysed production of C-GNPs and best achieved product concentration/conversion reported for the product. *enzymes used or coexpressed for the biotransformation processes other than $C$-GT are in parentheses, ${ }^{* *}$ UDP-glucose as glycosyl donor unless specified otherwise, ${ }^{2}$ TDPolivose was used as glycosyl donor. GmSuSy - sucrose synthase from G. max, PcOGT - phloretin O-GT from $P$. communis, PhF2H - CYP93G from $P$. heterocycla, OsF2H - CYP93G2 from O. sativa, Sb2FH - CYP93G3 from S. bicolor, n.p. - not provided. 
potential of these biosynthetic systems and provide the biochemical, structural and metabolic engineering knowledge that is important to overcome the challenges of applying C-GTs in biotechnology in the future such as low catalytic activity, insufficient stability, restricted substrate mass transfer, product inhibition and requirement of costly glycosyl donor substrates in stoichiometric amounts.

\subsection{In vitro synthesis of $C$-GNPs}

Overall, $C$-glycoside titres achieved in vitro are the highest so far (3$\left.50 \mathrm{~g} \cdot \mathrm{L}^{-1}\right) .{ }^{75-77}$ The antioxidant nothofagin (phloretin 3-C-glucoside) and bioactive flavone $C$-glucosides (isovitexin and isoorientin) have been produced via one-pot catalysis using purified recombinant OsCGT ${ }^{75,76}$ and GtUF6CGT1, ${ }^{77}$ respectively. In these processes, for sufficient supply of UDP-glucose, the activities of $C$-GTs were coupled with that of an UDP-glucose-regenerating enzyme, soybean sucrose synthase (GmSuSy)..$^{76}$ Further significant improvement in the titre of nothofagin (from 20 to $50 \mathrm{~g} \cdot \mathrm{L}^{-1}$ ) was achieved by overcoming the major bottleneck of the process: low solubility of the glycosyl acceptor phloretin through its complexation with 2-hydroxypropyl- $\beta$-cyclodextrin. ${ }^{75}$ Another established in vitro bioproduction process that use $C$-GTs is the synthesis of $C$-glycosides from related $O$-glycosides using reverse glycosyltransferase activity either via combined-enzyme catalysis or single-enzyme approach Successful examples of such processes are synthesis of nothofagin from phloretin 2-O-glucoside (phlorizin) using either two enzymes (the $O$-GT PCOGT that regenerates UDP-glucose and phlorizin from UDP and 2-O-glucoside phlorizin, while the C-GT OsCGT forms nothofagin and UDP from UDP-glucose and phlorizin) or bifunctional ones, such as OsCGT-I121D ${ }^{17,74}$ or MiCGTb. ${ }^{46}$

\subsection{In vivo production of $C$-GNPs}

In vivo production of C-GNPs has been achieved by different metabolic engineering strategies. They include one-step whole-cell $C$-glycosylation by recombinantly expressed C-GTs in E. coli, ${ }^{78,82}$ $C$-glycosylation by combined whole-cell enzyme systems co-expressing either cytochromes $\mathrm{P} 450$ in yeast $S$. cerevisiae ${ }^{80,81}$ or an enzyme "sugar" cassette in $E$. coli ${ }^{79}$ for the supply of C-glycosyl acceptors and glycosyl donors, respectively; and de novo synthesis of C-GNPs by introducing large natural or semi-natural synthetic pathways containing C-GT for the last reaction step. ${ }^{5,8}$ The titres of C-GNPs observed in vivo are generally much lower than those of in vitro with the highest product concentration of $0.97 \mathrm{~g} \cdot \mathrm{L}^{-1}$ that has been obtained for a $C$-glycosylated trihydroxyacetophenone with the previously described quadruple mutant MiCGTb-GAGM (S60G/V100A/T104G/I152M). ${ }^{39,82}$ The same enzyme variant was used for the synthesis of $C$-glucosylated coumarins, mono- and di-C-glucosyl acetophenones. ${ }^{82,83}$ Other $C$-GTs involved in whole-cell catalysis forming various 2-hydroxyflavanone, flavone, dihydrochalcone and acetophenone $C$-glycosides are summarised in Table 2 with the best/product titres or conversion. Moreover, an anhydrotetracycline 9-C-glycoside was biosynthesized using SsfS6 in E. coli50 and the production of the natural red pigment carminic acid was accomplished in the fungus Aspergillus nidulans and tobacco plant exploiting the insect $C$-GT DcUGT2. ${ }^{8,84}$

\section{Conclusions}

C-glycosylated intermediates and compounds are known to be synthesized in many plants, bacteria and insects, yet our current understanding of biological $C$-glycosylation remains limited. Reported C-GTs belong to the GT1 family, utilise a variety of nucleoside sugars donors and require substituted, electron-rich aromatic aglycons. According to current knowledge, the enzymes catalysing the formation of $C$-glycosidic bonds are however not phylogenetically, mechanistically or structurally different from their $\mathrm{O}$ - (or even $\mathrm{N}$ - and $\mathrm{S}$-) glycosylating counterparts. Often, a few of these activities are catalysed by the same enzyme, and one can only wonder if our current understanding of specificity is not a simple artefact of limited testing. With no known $C$-GT specific sequence motif, $C$-GT mining relying on database predictions cannot be implemented. Further, most GT assays rely on donor consumption and thus do not discriminate between $\mathrm{O}_{-}, \mathrm{N}-, \mathrm{S}$ - and $\mathrm{C}$-GT activities, and neither does one dimensional mass spectrometry. It is thus likely that a number of $C$-GTs have already been characterised but misreported as $O-G T s$. Hopefully, systematic investigations of GT-catalysed reactions will be prompted by researchers' growing awareness of $C$-GTs in the near future. The use of analytical $C$-glycosylated standards allows for a fast identification of a number of enzymes, though restricted to few specificities, as exemplified with the numerous recently discovered C-GTs that synthesize nothofagin or 2-hydroxynaringenin $C$-glycosides. However, the enzymes catalysing the vast majority of C-GNPS for which there is currently no standards are yet to be discovered.

More than half of the currently characterized C-GTs have been reported in the beginning of the current year, and we thus expect that the number of available enzymes will continue to dramatically expand in the near future. Going forward, nuclear magnetic resonance spectroscopy should be more systematically used in the GT research field to enable efficient and unambiguous identification of $C$-GTs with new specificities. Concomitantly, biotechnological use of GTs and other carbohydrate-active enzymes is booming, and we anticipate the application of C-GTs as unique natural tools for synthesizing novel or rare glycosides, natural or not. Engineered C-glycosylating variants of other GTs or of glycoside hydrolases are likely to be developed, potentially allowing the synthesis of unnatural $C$-glycosides such as aryl $\alpha$-L- $C$-glycopyranosides. Particularly, the availability of glycosyl donors is improving, either through reverse glycosylation using GTs in vitro, ${ }^{17,74,86}$ or synthases-catalysed ones for both vitro and vivo productions. ${ }^{75,79}$

\section{Conflicts of interest}

There are no conflicts to declare. 


\section{Acknowledgements}

This work was supported by the Novo Nordisk Foundation through grants NNF10CC1016517, NNF170C0025660 and NNF16OC0019088.

\section{References}

1 J. Xiao, E. Capanoglu, A. R. Jassbi and A. Miron, Crit. Rev. Food Sci. Nutr., 2016, 56, S29-S45.

2 C. J. Thibodeaux, C. E. Melançon and H. W. Liu, Angew. Chemie Int. Ed., 2008, 47, 9814-9859.

3 Q. Zhu, L. N. Mao, C. P. Liu, Y. H. Sun, B. Jiang, W. Zhang and J. X. Li, Sci. Rep., 2016, 6, 1-10.

4 M. He, J. W. Min, W. L. Kong, X. H. He, J. X. Li and B. W. Peng, Fitoterapia, 2016, 115, 74-85.

5 M. Eichenberger, B. J. Lehka, C. Folly, D. Fischer, S. Martens, E. Simón and M. Naesby, Metab. Eng., 2017, 39, 80-89.

6 M. Y. Park, H. J. Kwon and M. K. Sung, Life Sci., 2011, 88, 486492.

7 Z. Wang, X. Li, Z. Yang, X. He, J. Tu and T. V. Zhang, Int. J. Cosmet. Sci., 2008, 30, 121-130.

8 R. J. N. Frandsen, P. Khorsand-Jamal, K. T. Kongstad, M. Nafisi, R M. Kannangara, D. Staerk, F. T. Okkels, K. Binderup, B. Madsen, B. L. Møller, U. Thrane and U. H. Mortensen, Sci. Rep., 2018, 8, 12853.

9 F. L. C. Baranyovits, Endeavour, 1978, 2, 85-92.

10 Y. Yang and B. Yu, Chem. Rev., 2017, 117, 12281-12356.

11 H. Liao, J. Ma, H. Yao and X. W. Liu, Org. Biomol. Chem., 2018, 16, 1791.

12 K. Kitamura, Y. Ando, T. Matsumoto and K. Suzuki, Chem. Rev. 2018, 118, 1495-1598.

13 M. Charette and M. W. Gray, IUBMB Life, 2000, 49, 341-351.

14 S. Manabe, Y. Marui and Y. Ito, Chem. - A Eur. J., 2003, 9, 14351447.

15 T. Bililign, B. R. Griffith and J. S. Thorson, Nat. Prod. Rep., 2005 22, 742-760.

16 G. Tegl and B. Nidetzky, Biochem. Soc. Trans., 2020, 48, 15831598.

17 A. Gutmann and B. Nidetzky, Pure Appl. Chem., 2013, 85, 18651877.

18 A. P. Rauter, R. G. Lopes and A. Martins, Nat. Prod. Commun. 2014, 9, 1175-1196.

19 T. Eisner, S. Nowicki, M. Goetz and J. Meinwald, Science, 1980, 208, 1039-1042.

20 M. A. Fischbach, H. Lin, D. R. Liu and C. T. Walsh, Proc. Natl. Acad. Sci. U. S. A., 2005, 102, 571-576.

21 M. A. Fischbach, H. Lin, D. R. Liu and C. T. Walsh, Nat. Chem. Biol., 2006, 2, 132-138.

22 T. Laursen, J. Borch, C. Knudsen, K. Bavishi, F. Torta, H. J. Martens, D. Silvestro, N. S. Hatzakis, M. R. Wenk, T. R. Dafforn, C. E. Olsen, M. S. Motawia, B. Hamberger, B. L. Møller and J. E. Bassard Science, 2016, 354, 890-893.

23 T. M. Hsu, D. H. Welner, Z. N. Russ, B. Cervantes, R. L. Prathuri, P. D. Adams and J. E. Dueber, Nat. Chem. Biol., 2018, 14, 256-261.

24 T. Hosoya, Y. Ohashi, T. Matsumoto and K. Suzuki, Tetrahedron Lett., 1996, 37, 663-666.

25 K. Nakamura, K. Komatsu, M. Hattori and M. Iwashima, Biol. Pharm. Bull., 2013, 36, 635-640.

26 K. Nakamura, S. Zhu, K. Komatsu, M. Hattori and M. Iwashima, Biol. Pharm. Bull., 2019, 42, 417-423.

27 L. J. Haynes, in Advances in Carbohydrate Chemistry, eds. M. L. Wolfrom and R. Stuart Tipson, Academic Press, New York, 1963 pp. 227-258.

28 Y. Sun, Z. Chen, J. Yang, I. Mutanda, S. Li, Q. Zhang, Y. Zhang, Y. Zhang and Y. Wang, Commun. Biol., 2020, 3, 1-11.

29 V. Lombard, H. Golaconda Ramulu, E. Drula, P. M. Coutinho and
B. Henrissat, Nucleic Acids Res., 2014, 42, 490-495.

30 M. Brazier-Hicks, K. M. Evans, M. C. Gershater, H. Puschmann, P. G. Steel and R. Edwards, J. Biol. Chem., 2009, 284, 17926-17934.

31 M. L. F. Ferreyra, E. Rodriguez, M. I. Casas, G. Labadie, E. Grotewold and P. Casati, J. Biol. Chem., 2013, 288, 31678-31688.

32 Y. Hirade, N. Kotoku, K. Terasaka, Y. Saijo-Hamano, A. Fukumoto and H. Mizukami, FEBS Lett., 2015, 589, 1778-1786.

33 Y. Nagatomo, S. Usui, T. Ito, A. Kato, M. Shimosaka and G. Taguchi, Plant J., 2014, 80, 437-449.

34 X. Wang, C. Li, C. Zhou, J. Li and Y. Zhang, Plant J., 2017, 90, 535546.

35 M. Zhang, F.-D. Li, K. Li, Z.-L. Wang, Y.-X. Wang, J.-B. He, H.-F. Su, Z.-Y. Zhang, C.-B. Chi, X.-M. Shi, C.-H. Yun, Z.-Y. Zhang, Z. Liu, L.R. Zhang, D.-H. Yang, M. Ma, X. Qiao and M. Ye, J. Am. Chem. Soc., 2020, 142, 3506-3512.

36 T. Ito, S. Fujimoto, F. Suito, M. Shimosaka and G. Taguchi, Plant J., 2017, 91, 187-198.

37 N. Sasaki, Y. Nishizaki, E. Yamada, F. Tatsuzawa, T. Nakatsuka, H. Takahashi and M. Nishihara, FEBS Lett., 2015, 589, 182-187.

38 J. Bin He, P. Zhao, Z. M. Hu, S. Liu, Y. Kuang, M. Zhang, B. Li, C. H. Yun, X. Qiao and M. Ye, Angew. Chemie - Int. Ed., 2019, 58, 11513-11520.

39 D. Chen, S. Fan, R. Chen, K. Xie, S. Yin, L. Sun, J. Liu, L. Yang, J. Kong, Z. Yang and J. Dai, ACS Catal., 2018, 8, 4917-4927.

40 K. Mashima, M. Hatano, H. Suzuki, M. Shimosaka and G. Taguchi, Plant Cell Physiol., 2019, 60, 2733-2743.

41 F. Gandia-Herrero, A. Lorenz, T. Larson, I. A. Graham, D. J. Bowles, E. L. Rylott and N. C. Bruce, Plant J., 2008, 56, 963-974.

42 J. Ati, P. Lafite and R. Daniellou, Beilstein J. Org. Chem., 2017, 13, 1857-1865.

43 D. Chen, R. Chen, R. Wang, J. Li, K. Xie, C. Bian, L. Sun, X. Zhang, J. Liu, L. Yang, F. Ye, X. Yu and J. Dai, Angew. Chemie, 2015, 127, 12869-12873.

44 F. Kerscher and G. Franz, Zeitschrift fur Naturforsch. - Sect. C J. Biosci., 1987, 42, 519-524.

45 F. Kerscher and G. Franz, J. Plant Physiol., 1988, 132, 110-115.

46 D. Chen, L. Sun, R. Chen, K. Xie, L. Yang and J. Dai, Chem. - A Eur. J., 2016, 22, 5873-5877.

47 C. Dürr, D. Hoffmeister, S. E. Wohlert, K. Ichinose, M. Weber, U. Von Mulert, J. S. Thorson and A. Bechthold, Angew. Chemie - Int Ed., 2004, 43, 2962-2965.

48 E. Künzel, B. Faust, C. Oelkers, U. Weissbach, D. W. Bearden, G. Weitnauer, L. Westrich, A. Bechthold and J. Rohr, J. Am. Chem. Soc., 1999, 121, 11058-11062.

49 A. Trefzer, D. Hoffmeister, E. Künzel, S. Stockert, G. Weitnauer, L. Westrich, U. Rix, J. Fuchser, K. U. Bindseil, J. Rohr and A. Bechthold, Chem. Biol., 2000, 7, 133-142.

50 L. Li, P. Wang and Y. Tang, J. Antibiot. (Tokyo)., 2014, 67, 65-70.

51 R. Kannangara, L. Siukstaite, J. Borch-Jensen, B. Madsen, K. T. Kongstad, D. Staerk, M. Bennedsen, F. T. Okkels, S. A. Rasmussen, T. O. Larsen, R. J. N. Frandsen and B. L. Møller, Nat. Commun., 2017, 8, 1987

52 T. Liu, M. K. Kharel, C. Fischer, A. McCormick and J. Rohr ChemBioChem, 2006, 7, 1070-1077.

53 A. Erb, A. Luzhetskyy, U. Hardter and A. Bechthold, ChemBioChem, 2009, 10, 1392-1401.

54 F. Wang, M. Zhou, S. Singh, R. M. Yennamalli, C. A. Bingman, J. S. Thorson and G. N. Phillips, Proteins Struct. Funct. Bioinforma., 2013, 81, 1277-1282.

55 D. Hoffmeister, G. Dräger, K. Ichinose, J. Rohr and A. Bechthold J. Am. Chem. Soc., 2003, 125, 4678-4679.

56 K. Ichinose, D. J. Bedford, D. Tornus, A. Bechthold, M. J. Bibb, W P. Revill, H. G. Floss and D. A. Hopwood, Chem. Biol., 1998, 5, 647-659.

57 K. Ichinose, M. Ozawa, K. Itou, K. Kunieda and Y. Ebizuka Microbiology, 2003, 149, 1633-1645.

58 B. Faust, D. Hoffmeister, G. Weitnauer, L. Westrich, S. Haag, P. Schneider, H. Decker, E. Künzel, J. Rohr and A. Bechthold, 
Microbiology, 2000, 146, 147-154.

59 M. Mittler, A. Bechthold and G. E. Schulz, J. Mol. Biol., 2007, 372, 67-76.

60 A. Trefzer, G. Blanco, L. Remsing, E. Künzel, U. Rix, F. Lipata, A. F. Braña, C. Méndez, J. Rohr, A. Bechthold and J. A. Salas, J. Am. Chem. Soc., 2002, 124, 6056-6062.

61 A. Luzhetskyy, T. Taguchi, M. Fedoryshyn, C. Dürr, S. E. Wohlert, V. Novikov and A. Bechthold, ChemBioChem, 2005, 6, 14061410.

62 D. Hoffmeister, K. Ichinose, S. Domann, B. Faust, A. Trefzer, G. Dräger, A. Kirschning, C. Fischer, E. Künzel, D. W. Bearden, J. Rohr and A. Bechthold, Chem. Biol., 2000, 7, 821-831.

63 B. Bister, D. Bischoff, G. J. Nicholson, M. Valdebenito and K. Hantke, BioMetals, 2004, 17, 471-481.

64 D. Foshag, C. Campbell and P. D. Pawelek, Biochim. Biophys. Acta - Proteins Proteomics, 2014, 1844, 1619-1630.

65 Y. Hu and S. Walker, Chem. Biol., 2002, 9, 1287-1296.

66 A. M. Mulichak, H. C. Losey, C. T. Walsh and R. M. Garavito, Structure, 2001, 9, 547-557.

67 L. L. Lairson, B. Henrissat, G. J. Davies and S. G. Withers, Annu. Rev. Biochem., 2008, 77, 521-555.

68 J. Härle, S. Günther, B. Lauinger, M. Weber, B. Kammerer, D. L. Zechel, A. Luzhetskyy and A. Bechthold, Chem. Biol., 2011, 18, 520-530.

69 A. Gutmann and B. Nidetzky, Angew. Chemie - Int. Ed., 2012, 51 12879-12883.

70 H. K. Tam, J. Härle, S. Gerhardt, J. Rohr, G. Wang, J. S. Thorson, A Bigot, M. Lutterbeck, W. Seiche, B. Breit, A. Bechthold and O. Einsle, Angew. Chemie - Int. Ed., 2015, 54, 2811-2815.

71 A. Lepak, A. Gutmann and B. Nidetzky, ACS Catal., 2018, 8, 91489153.

72 M. Liu, D. Wang, Y. Li, X. Li and G. Zong, Plant Cell, 2020, online ahead of print.

73 G. R. Strichartz, G. S. Oxford and F. Ramon, Biophys. J., 1980, 31, 229-246.

74 A. Gutmann, C. Krump, L. Bungaruang and B. Nidetzky, Chem. Commun., 2014, 50, 5465-5468.

75 K. Schmölzer, M. Lemmerer and B. Nidetzky, Biotechnol. Bioeng., 2018, 115, 545-556.

76 L. Bungaruang, A. Gutmann and B. Nidetzky, Adv. Synth. Catal., 2013, 355, 2757-2763.

77 J. Pei, Q. Sun, N. Gu, L. Zhao, X. Fang, F. Tang and F. Cao, Appl. Biochem. Biotechnol., 2020, 190, 601-615.

78 T. Ito, S. Fujimoto, M. Shimosaka and G. Taguchi, Plant Biotechnol., 2014, 31, 519-524.

79 A. Shrestha, R. P. Pandey, D. Dhakal, P. Parajuli and J. K. Sohng Appl. Microbiol. Biotechnol., 2018, 102, 1251-1267.

80 K. G. Vanegas, A. B. Larsen, M. Eichenberger, D. Fischer, U. H. Mortensen and M. Naesby, Microb. Cell Fact., 2018, 17, 1-10.

81 M. Brazier-Hicks and R. Edwards, Metab. Eng., 2013, 16, 11-20.

82 D. Chen, R. Chen, K. Xie, Y. Duan and J. Dai, Tetrahedron Lett., 2018, 59, 1875-1878.

83 D. Chen, R. Chen, K. Xie, T. Yue, X. Zhang, F. Ye and J. Dai, Org. Lett., 2018, 20, 1634-1637.

84 J. Andersen-Ranberg, K. T. Kongstad, M. Nafisi, D. Staerk, F. T. Okkels, U. H. Mortensen, B. Lindberg Møller, R. J. N. Frandsen and R. Kannangara, ChemBioChem, 2017, 18, 1893-1897.

85 B. Nidetzky, A. Gutmann and C. Zhong, ACS Catal., 2018, 8, 62836300.

86 R. W. Gantt, P. Peltier-Pain, W. J. Cournoyer and J. S. Thorson, Nat. Chem. Biol., 2011, 7, 685-691. 